\title{
Prognostic significance of the tumor suppressor protein p53 gene in childhood acute lymphoblastic leukemia
}

\author{
WENWEN WENG ${ }^{*}$, PING ZHANG* ${ }^{*}$ JINFEI RUAN, YAO ZHANG, DIANDIAN BA and YONGMIN TANG \\ Division of Hematology-Oncology, Children's Hospital of Zhejiang University School of Medicine, \\ Hangzhou, Zhejiang 310003, P.R. China
}

Received March 29, 2019; Accepted August 8, 2019

DOI: $10.3892 /$ ol.2019.11064

\begin{abstract}
The tumor suppressor protein p53 (TP53) gene is associated with various types of cancer; however, little is known about TP53 expression in patients with childhood acute lymphoblastic leukemia (ALL). The aim of the present study was to investigate the prognostic value of TP53 expression in childhood ALL. To achieve this, TP53 mRNA levels of 146 children with ALL and 23 child donors with idiopathic thrombocytopenic purpura were determined by reverse transcription-quantitative PCR. Relapse-free survival (RFS) and overall survival (OS) were analyzed using the Kaplan-Meier method. The results demonstrated that TP53 mRNA level in patients with ALL was higher compared with that in the ITP donors $(\mathrm{P}=0.019)$. Patients with highly-expressed TP53 exhibited lower percentages of peripheral blood blast, higher platelet counts and inferior complete remission rates compared with patients with low expression of TP53. Survival analyses revealed that high TP53 expression was associated with poor OS and RFS in childhood ALL $(\mathrm{P}=0.018$ and $\mathrm{P}=0.028$, respectively) and was an independent prognostic factor in multivariate analysis for poor RFS $(\mathrm{P}<0.001)$ and OS $(\mathrm{P}<0.001)$. In conclusion, high TP53 expression is associated with poor outcomes and may be used as a molecular prognostic marker to be incorporated into an improved risk classification system for childhood ALL.
\end{abstract}

\section{Introduction}

Acute lymphoblastic leukemia (ALL) is the most common malignancy in children (1). In the worldwide pediatric

Correspondence to: Dr Yongmin Tang, Division of Hematology-Oncology, Children's Hospital of Zhejiang University School of Medicine, 57 Zhuganxiang Road, Yan-an Street, Hangzhou, Zhejiang 310003, P.R. China

E-mail: y_m_tang@zju.edu.cn

*Contributed equally

Key words: tumor suppressor protein 53, acute lymphoblastic leukemia, childhood, survival, prognosis population, ALL accounts for $81 \%$ of childhood leukemias; leukemia overall accounts for one third of cancers diagnosed in children between ages of 0 to 14 years (1). With the development of contemporary treatment regimens and advances in epigenomic and genomic profiling, the overall survival (OS) in pediatric patients with ALL is $>80 \%$, and our understanding of the biology of ALL relapse has remarkably improved and facilitated more precise risk determination during the past 10 years $(2,3)$. However, $20-35 \%$ of patients with ALL experience relapse, and treating relapsed ALL patients is challenging (4-6). ALL commonly arises from a series of genetic alterations, which may occur due to inherited susceptibility, exogenous or endogenous exposure to various mutagens or, rarely, by chance $(7,8)$. Over the past three decades, several traditional cytogenetic studies of genetic aberrations including chromosomal translocations and alterations in chromosome numbers have provided information on the pathogenesis of ALL (7). To identify potential molecular targets of ALL, it is crucial to study leukemic cell and host genetics, as well as to identify new prognostic markers to optimize individualized therapy, especially for high-risk groups and relapsed patients (6).

Tumor suppressor protein p53 (TP53) is a gene encoding a protein that acts as a cellular stress sensor, which is activated by stress conditions such as DNA damage and oncogene activation; TP53 induces cell cycle arrest, senescence, apoptosis or changes in metabolism (9). Wild-type TP53 has been demonstrated to suppress tumor development and TP53-mediated protein synthesis, and has been further examined in mouse models, for example, TP53 knockout mice and mice with loss-of-function mutations in TP53 develop spontaneous tumors with $100 \%$ incidence by 9 months of age (10). TP53 is the most commonly mutated gene in cancers; mutations have been identified in various types of cancer and serve as independent markers of poor prognosis in breast carcinoma, Waldenstrom's macroglobulinemia, non-Hodgkin lymphoma, medulloblastoma and several other types of cancer $(9,11-14)$. In addition, median progression-free survival and overall survival (OS) of TP53-mutated adult patients with chronic lymphocytic leukemia were significantly decreased, indicating that TP53 mutations may be an adverse prognosis factor independent of the presence of the $17 \mathrm{p}$ deletion (15). However, TP53 expression and the impact on prognosis is poorly defined in childhood ALL. Therefore, the aim of the present study was 
to investigate TP53 expression and analyze its clinical significance in patients with childhood ALL.

\section{Materials and methods}

Patients. In this retrospective study, a total of 146 patients with childhood ALL were enrolled, including 60 girls and 86 boys with a median age of 6 years (range, 1-14 years). All patients were newly diagnosed with ALL and were consecutively treated in the Children's Hospital of Zhejiang University School of Medicine (Hangzhou, China) between January 2007 and September 2010. Morphological, cytogenetic, immunologic and molecular characterization criteria were routinely used to diagnose ALL. The immunophenotypes of the patient included B-lineage ALL (B-ALL; $n=114$ ) and T-lineage ALL (T-ALL; $n=32$ ). High risk patients (6 cases of B-ALL and 6 cases of T-ALL) underwent hematopoietic stem/progenitor cell transplantation (HSCT). A total of 23 patients with idiopathic thrombocytopenic purpura (ITP) were recruited for the control group, including 9 girls and 14 boys with a median age of 5 years (range, 2-12 years), after written informed consents were obtained from their parents or guardians. A total of 146 bone marrow (BM) samples were collected at the time of diagnosis and $23 \mathrm{BM}$ samples from de novo ITP patients at the time of diagnosis. As peripheral blood (PB) taken at the time of diagnosis for patients produced similar results as those taken using BM samples, this was decided to be the main focus of the study. All treatment protocols were in accordance with the Declaration of Helsinki and approved by the Institutional Review Board of Ethics of Children's Hospital of Zhejiang University School of Medicine. Written informed consent was obtained from the parents or guardians of all patients.

All patients received a modified National Protocol of Childhood ALL in China 1997 (NPCAC97) (16). Patients were classified into a low-risk group if they exhibited all of the following features: i) Age, 1-10 years; ii) initial white blood cell (WBC) count $<5 \times 10^{10}$ cells $/ 1$; iii) good prednisone response ( $<1,000$ blasts $/ \mu \mathrm{l})$; iv) not $\mathrm{T}$ cell or mature B cell types; v) no translocation $(\mathrm{t})(9 ; 22), \mathrm{t}(1 ; 19)$ or mixed lineage leukemia (MLL) rearrangements; vi) bone marrow morphology was M1 on day 15 or day 33; vii) no central nervous system or testicular leukemia at diagnosis; and viii) minimal residual disease $(\mathrm{MRD})<1 \times 10^{-4}$ on day 33 . Patients aged $>10$ years, with initial WBC between $5 \times 10^{10}$ and $1 \times 10^{11}$ cells $/ 1$, extramedullary involvement at diagnosis, T-ALL or hypodiploidy ( $<45$ chromosomes) were considered intermediate risk. Patients aged $<1$ year old, or with initial WBC counts $\geq 100 \times 10^{9} / 1$, or with $\mathrm{t}(9 ; 22), \mathrm{t}(4 ; 11)$ or BCR/ABL1, MLL/AF4 (the fusion of the MLL gene on chromosome 11 and the AF4 gene on chromosome 4) fusion genes, or poor response to prednisone or not achieving complete remission (CR) on day 42 were considered high risk. The median follow-up time was 96 months (range, 1-139 months).

$R N A$ extraction and reverse transcription-quantitative PCR $(R T-q P C R)$. Mononucleated cells from 146 cryopreserved $\mathrm{BM}$ stored in liquid nitrogen and $23 \mathrm{BM}$ samples from non-hematological malignancy disease, i.e. ITP, were isolated by Ficoll gradient centrifugation, at $350 \mathrm{x}$ g for $20 \mathrm{~min}$ at $4^{\circ} \mathrm{C}$. Total RNA was extracted using the High Pure RNA Isolation kit (Roche Diagnostics $\mathrm{GmbH}$ ) according to the manufacturer's instructions, and RNA was reverse-transcribed into cDNA using the ReverTra Ace qPCR RT kit (Toyobo Life Science) according to the manufacturer's protocol. The thermocycling conditions were as follows: $65^{\circ} \mathrm{C}$ for $5 \mathrm{~min}$, followed by $37^{\circ} \mathrm{C}$ for $15 \mathrm{~min}$ and $98^{\circ} \mathrm{C}$ for $5 \mathrm{~min}$.

qPCR was performed to determine the TP53 mRNA levels on a StepOnePlus ${ }^{\mathrm{TM}}$ Real-time PCR system (Applied Biosystems; Thermo Fisher Scientific, Inc.) using GAPDH as an internal reference gene. All samples were run in triplicates to reduce the chance of errors. The primer sequences for TP53 amplification were designed using the Primer 5 software (version 5.0; Premier Biosoft International) and the sequences are as follows: TP53 forward, 5'-GCGTGTTTGTGCCTGTCC TG-3' and reverse, 5'-GTGCTCGCTTAGTGCTCCCT-3' and GAPDH forward, 5'-GAAGGTGAAGGTCGGAGTC-3' and reverse, 5'-GAAGATGGTGATGGGATTTC-3'. GAPDH was used as the internal control. Each mixture was composed of $2 \mu \mathrm{g}$ cDNA, $1 \mu \mathrm{l}$ TP53 or GAPDH primers (10 $\mu \mathrm{mol} / \mathrm{l}), 12.5 \mu \mathrm{l}$ SYBR $^{\circledR}$-Green PCR Master mix (Toyobo Life Science) and deionized water to a total volume of $25 \mu \mathrm{l}$. The thermocycling conditions were as follows: $95^{\circ} \mathrm{C}$ for $5 \mathrm{~min}$, followed by 30 cycles of $94^{\circ} \mathrm{C}$ for $30 \mathrm{sec}, 62^{\circ} \mathrm{C}$ for $30 \mathrm{sec}$ and $72^{\circ} \mathrm{C}$ for $70 \mathrm{sec}, 72^{\circ} \mathrm{C}$ for $10 \mathrm{~min}$ and $4^{\circ} \mathrm{C}$ for $20 \mathrm{~min}$. The comparative cycle quantification $(\mathrm{Cq})$ value of the patient samples was used to determine the relative expression levels of TP53 to GAPDH. The cycle number difference $\left(\Delta \mathrm{C}_{\mathrm{q}}=\mathrm{TP} 53-\mathrm{GAPDH}\right)$ was counted for each of the triplicates, calculated using the mean value and expressed as $2^{-\Delta \Delta \mathrm{Cq}}(17)$.

Survival analysis. Relapse-free survival (RFS) was defined as the time between the first CR and relapse, death, second tumor or last contact with patients. Overall survival (OS) was defined as the time between the diagnosis and death or last contact with patients. The end of the follow-up period was September 2018. RFS and OS were analyzed using the Kaplan-Meier method and log-rank test, while Cox regression model was used for univariate and multivariate analyses.

Statistical analysis. The median TP53 value was selected to divide patients into low- and high-TP53 expression groups. Comparisons of continuous variables between two groups were performed using the nonparametric Mann-Whitney U test. Pearson's $\chi^{2}$ or Fisher's exact test were used to compare the differences between categorical variables. All analyses were performed using GraphPad Prism v.5.01 (GraphPad Software, Inc.) and SPSS 25.0 (IBM Corp.). $\mathrm{P}<0.05$ was considered to indicate a statistically significant difference.

\section{Results}

Association between TP53 expression and patient clinicopathological characteristics. The level of TP53 mRNA was increased in patients with ALL compared with ITP controls $(\mathrm{P}=0.019$; Fig. 1A). For statistical analyses, patients were divided into high- and low-TP53 expression groups according to the median value. Associations between TP53 expression and clinical and molecular features, including age, sex, WBC, PB blasts and platelet count (PLT) at diagnosis, extramedullary involvement, immunophenotype, risk stratification, breakpoint 

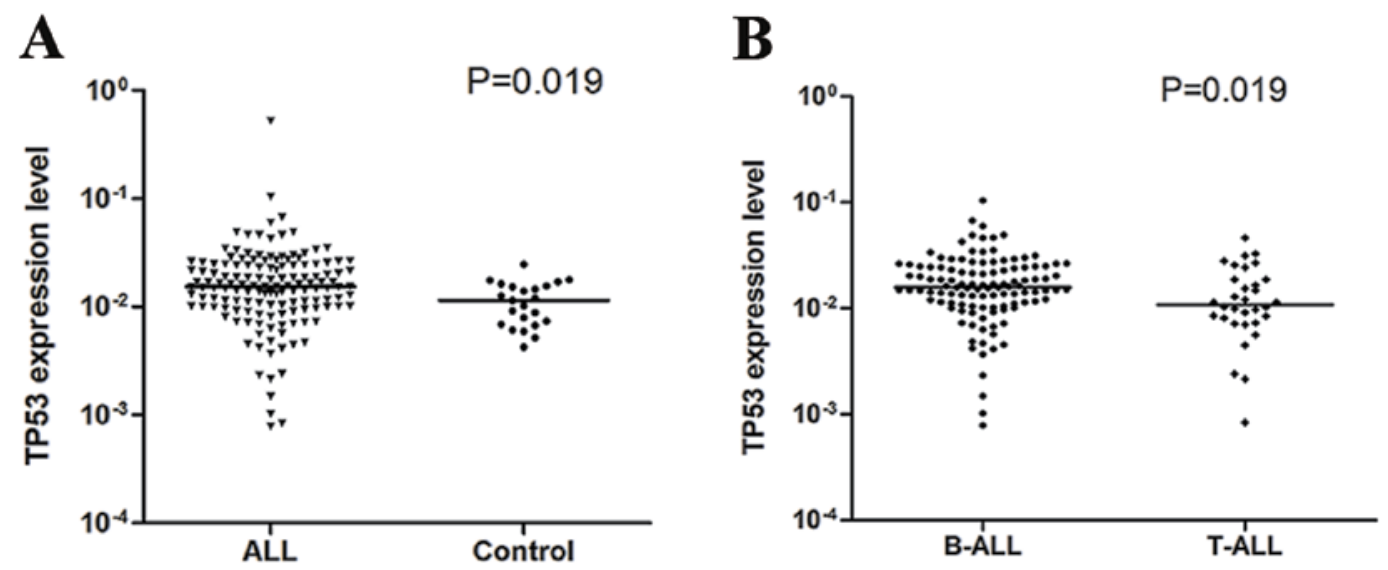

Figure 1. TP53 expression in childhood ALL. Relative expression levels of TP53 ( $\log 10$ scale on the y axis). Horizontal lines represent the median. (A) TP53 exhibited higher expression levels in patients with ALL $(n=146)$ compared with ITP controls $(n=23)$. (B) In B-ALL ( $n=114)$, TP53 expression was significantly higher compared with that in T-ALL ( $\mathrm{n}=32$ ). TP53, tumor suppressor protein p53; ALL, acute lymphoblastic leukemia; B-ALL, B-cell ALL; T-ALL, T-cell ALL.

cluster region/ABL proto-oncogene 1 (BCR/ABL1) and MLL/AF4-FMR2 family member 1 (MLL/AF4) fusion genes and MRD levels on days 15 and 33, were compared between the two groups. Overall, patients in the high-TP53 expression group exhibited lower PB blast percentages (median, 10 vs. $25 \%$; $\mathrm{P}=0.025$ ) and a higher PLT count (median, $70 \times 10^{9}$ vs. $52 \times 10^{9}$ cells $/ 1$; $\mathrm{P}=0.043$ ). However, no significant association was observed between TP53 expression level and sex, age, WBC count, BM blasts, extramedullary involvement, risk groups, presence of BCR/ABL1 or MLL/AF4 fusion genes and MRD on day 15 or 33 (Table I).

TP53 is a risk factor in childhood ALL. Patients in the high-TP53 expression group exhibited poorer $\mathrm{CR}$ rates compared with those in the low-expression group ( 85 vs. $96 \% ; \mathrm{P}=0.025$ ); however, no association was observed in the prednisone response between the two groups ( 87 vs. $79 \%$; $P=0.387$ ). In addition, relapse rates between the low- and high-TP53 expression groups (19 vs. $26 \% ; \mathrm{P}=0.259$ ) were not significantly different (Table II). Compared with the low-TP53 expression group, the OS rate of the high-TP53 expression group was significantly lower, with the 5-year OS rate of 73 vs. 88\% [95\% confidence interval (CI), 65-82 vs. $78-97 \%$; $\mathrm{P}=0.018$; Fig. $2 \mathrm{~A}]$. In addition, a significant difference was identified between the 5-year RFS rates of the low- and high-TP53 expression groups (median, 86 vs. $71 \%$; 95\% CI, 77-95 vs. 61-80\%; P=0.028; Fig. 2B).

Multivariate analyses using the Cox proportional hazards model revealed that in patients with childhood ALL, TP53 was an independent prognostic factor for OS and RFS. For OS, the hazard of death from any cause for patients in the high-TP53 expression group was $>3$-fold higher compared with patients in the low-TP53 expression group [hazard ratio $(\mathrm{HR})=6.865$; 95\% CI, 2.665-17.685; P<0.001; Table III). High TP53 expression was a poor independent prognostic factor for RFS with a HR of 5.832 (95\% CI, 2.340-14.533; P<0.001; Table III). However, sex, age, WBC count, BM blasts, PB blasts, MRD on day 15 or 33, risk group and BCR/ABL1 fusion gene had no predictive value in the prognosis of OS and RFS.

Outcomes and prognostic significance of TP53 expression in patients with B-ALL and T-ALL. Median TP53 gene expression was higher in B-ALL compared with that in T-ALL ( $\mathrm{P}=0.019$; Fig. 1B). TP53 expression levels were further investigated in 114 patients with B-ALL. Among the clinical and molecular features, only BM blasts were significantly different between the high- and low-TP53 expression groups (median, 89 vs. 92\%; $\mathrm{P}=0.040$; Table IV). The association between TP53 expression levels and outcomes in patients with B-ALL was subsequently analyzed. The patients in the low-TP53 expression group exhibited a higher 5-year OS rate (89 vs. $75 \%$; $95 \%$ CI, 79-98 vs. 66-85\%; $\mathrm{P}=0.036$; Table IV; Fig. 2C) and a higher 5-year RFS rate (87 vs. 68\%; 95\% CI, 78-97\% vs. 59-76\%; P=0.045; Table IV; Fig. 2D) compared with the high-TP53 expression group. In addition, the high-TP53 expression group exhibited a lower CR rate compared with the low-TP53 expression group (84 vs. 98\%; $\mathrm{P}=0.011)$. No significant differences were observed between the two groups in induction regimen $(\mathrm{P}=0.622)$ or relapse rates $(\mathrm{P}=0.779)$. For patients with $\mathrm{B}-\mathrm{ALL}$, results from multivariate analysis with Cox proportional hazards model revealed that the upregulation of TP53 was an independent prognostic factor for poor OS $(\mathrm{HR}=6.436 ; 95 \% \mathrm{CI}$, 2.167-19.115; $\mathrm{P}=0.001$; Table V). $\mathrm{CR}$ was also an independent prognostic factor for OS $(\mathrm{HR}=0.175 ; 95 \% \mathrm{CI}, 0.048-0.641$; $\mathrm{P}=0.008$; Table $\mathrm{V})$. In addition, high TP53 expression $(\mathrm{HR}=6.026 ; 95 \% \mathrm{CI}, 2.050-17.717 ; \mathrm{P}=0.001)$ and $\mathrm{CR}$ $(\mathrm{HR}=0.2577 ; 95 \% \mathrm{CI}, 0.073-0.900 ; \mathrm{P}=0.034$; Table $\mathrm{V})$ were independent prognostic factors for RFS.

Analysis of the association between TP53 expression and patient outcomes was also performed in 32 patients with T-ALL. Among all the clinical features, no statistical differences were observed between the high- and low-TP53 expression groups. However, in survival analyses, significant differences were observed between the low- and high-TP53 groups in OS and RFS ( $\mathrm{P}<0.05$; Fig. $2 \mathrm{E}$ and $\mathrm{F})$.

\section{Discussion}

Progress in ALL treatment development has led to a cure rate of $>80 \%$ in children; however, a certain number of patients experience relapse (18). TP53 is a crucial tumor suppressor gene responsible for major defense against tumor growth as 
Table I. Clinicopathological characteristics of patients with high and low expression levels of TP53 expression.

\begin{tabular}{|c|c|c|c|}
\hline Characteristic & Low TP53 (n=73) & High TP53 (n=73) & P-value \\
\hline Age, years & & & 0.696 \\
\hline Median & 6 & 6 & \\
\hline Range & $1-14$ & $1-14$ & \\
\hline Sex, male, n (\%) & $42(58)$ & $44(60)$ & 0.737 \\
\hline WBC count, $\mathrm{x} 10^{9}$ cells $/ 1$ & & & 0.181 \\
\hline Median & 23.6 & 20.2 & \\
\hline Range & $0.14-385.60$ & $0.80-888.40$ & \\
\hline PB blasts, $\%$ & & & $0.025^{\mathrm{a}}$ \\
\hline Median & 25 & 10 & \\
\hline Range & $0-85$ & $0-75$ & \\
\hline BM blasts, $\%$ & & & 0.219 \\
\hline Median & 90 & 89 & \\
\hline Range & $56-97$ & $23-98$ & \\
\hline PLT count, $\times 10^{9}$ cells $/ 1$ & & & $0.043^{\mathrm{a}}$ \\
\hline Median & 52 & 70 & \\
\hline Range & $10-359$ & $4-375$ & \\
\hline Extramedullary involvement, $\mathrm{n}(\%)$ & & & 0.317 \\
\hline Yes & $3(4)$ & $1(1)$ & \\
\hline Immunophenotype, $\mathrm{n}(\%)$ & & & 0.054 \\
\hline B-ALL & $52(71)$ & $62(85)$ & \\
\hline T-ALL & $21(29)$ & $11(15)$ & \\
\hline Risk, n (\%) & & & 0.264 \\
\hline Low & $27(37)$ & $18(25)$ & \\
\hline Intermediate & $17(23)$ & $19(26)$ & \\
\hline High & $29(40)$ & $36(49)$ & \\
\hline BCR/ABL1, n (\%) & & & 0.754 \\
\hline Present & $6(8)$ & $5(7)$ & \\
\hline Absent & $67(92)$ & $68(93)$ & \\
\hline MLL/AF4, n (\%) & & & 1.000 \\
\hline Present & $1(1)$ & $1(1)$ & \\
\hline Absent & 72 (99) & $72(99)$ & \\
\hline Day 15 MRD, n (\%) & & & 0.501 \\
\hline$\geq 0.01 \%$ & $28(38)$ & $32(44)$ & \\
\hline$<0.01 \%$ & $45(62)$ & $41(56)$ & \\
\hline Day 33 MRD, n (\%) & & & 0.081 \\
\hline$\geq 0.01 \%$ & $51(70)$ & $60(82)$ & \\
\hline$<0.01 \%$ & $22(30)$ & $13(18)$ & \\
\hline
\end{tabular}

${ }^{\mathrm{a}} \mathrm{P}<0.05$. TP53, tumor suppressor protein p53; ALL, acute lymphoblastic leukemia; B-ALL, B-cell ALL; T-ALL, T-cell ALL; WBC, white blood cell; PB, peripheral blood; BM, bone marrow; PLT, platelet; BCR, breakpoint cluster region; ABL1, ABL proto-oncogene 1, non-receptor tyrosine kinase; MLL, lysine methyltransferase 2A; AF4, AF4/FMR2 family member 1; MRD, minimal residual disease.

it promotes autophagy, apoptosis signaling, transcription, immune or inflammatory responses $(10,18,19)$. In addition, TP53 is an extensively studied gene in a variety of types of cancer, including hematopoietic malignancies, especially in acute myeloid leukemia (20-24). A previous study demonstrated that TP53 upregulation predicts poor outcome in human laryngeal squamous cell carcinoma (25). The present study aimed to identify the association between the levels of TP53 expression and childhood ALL. To the best of our knowledge, this is the first study to focus on TP53 mRNA levels in patients with childhood ALL.

In the present study, TP53 expression was determined in 146 patients with childhood ALL to test whether TP53 mRNA levels had impact on treatment outcomes. The results demonstrated that the expression of TP53 in patients with childhood ALL was significantly higher compared with that in the 
Table II. Patient outcomes according to TP53 expression levels.

\begin{tabular}{llll}
\hline Outcome & Low TP53 & High TP53 & P-value \\
\hline Induction regimen-sensitive, n (\%) & $62(85)$ & $58(79)$ & 0.387 \\
CR, n (\%) & $70(96)$ & $62(85)$ & $0.025^{\mathrm{a}}$ \\
Relapse, n (\%) & $13(19)$ & $16(26)$ & 0.259 \\
5-year RFS, \% (95\% CI) & $86(77-95)$ & $71(61-80)$ & $0.028^{\mathrm{a}}$ \\
5-year OS, \% (95\% CI) & $88(78-97)$ & $73(65-82)$ & $0.018^{\mathrm{a}}$ \\
\hline
\end{tabular}

${ }^{\mathrm{a}} \mathrm{P}<0.05$. CI, confidence interval; CR, complete remission; RFS, relapse-free survival; OS, overall survival.

Table III. Multivariate analyses for RFS and OS in patients with childhood ALL.

\begin{tabular}{|c|c|c|c|c|c|c|}
\hline \multirow[b]{2}{*}{ Factor } & \multicolumn{3}{|c|}{ OS } & \multicolumn{3}{|c|}{ RFS } \\
\hline & HR & $95 \% \mathrm{CI}$ & P-value & $\mathrm{HR}$ & $95 \% \mathrm{CI}$ & P-value \\
\hline TP53 expression (high vs. low) & 6.865 & $2.665-17.685$ & $<0.001^{\mathrm{a}}$ & 5.832 & $2.340-14.533$ & $<0.001^{\mathrm{a}}$ \\
\hline Sex (male vs. female) & 2.184 & $0.949-5.029$ & 0.066 & 2.228 & $0.973-5.863$ & 0.083 \\
\hline Age ( $\geq 10$ vs. $<10$ years $)$ & 1.425 & $0.625-3.248$ & 0.400 & 1.537 & $0.675-3.500$ & 0.306 \\
\hline WBC count $\left(\geq 50 \times 10^{9}\right.$ vs. $<50 \times 10^{9}$ cells $\left./ 1\right)$ & 1.835 & $0.527-6.395$ & 0.340 & 1.494 & $0.435-5.128$ & 0.524 \\
\hline BM blasts ( $\geq$ median vs. $<$ median $)$ & 0.770 & $0.336-1.7610$ & 0.535 & 0.760 & $0.335-1.725$ & 0.511 \\
\hline PB blasts ( $\geq$ median vs. $<$ median) & 1.295 & $0.412-4.066$ & 0.658 & 1.452 & $0.464-4.539$ & 0.522 \\
\hline Risk (high vs. low + intermediate) & 2.000 & $0.741-5.396$ & 0.171 & 1.675 & $0.640-4.381$ & 0.293 \\
\hline CR (no vs. yes) & 1.061 & $0.240-4.684$ & 0.937 & 0.985 & $0.217-4.480$ & 0.984 \\
\hline BCR-ABL1 (present vs. absent) & 0.774 & $0.172-3.494$ & 0.739 & 0.613 & $0.137-2.750$ & 0.523 \\
\hline Day 15 MRD ( $\geq 0.01$ vs. $<0.01 \%$ ) & 0.840 & $0.325-2.171$ & 0.718 & 0.945 & $0.355-2.510$ & 0.909 \\
\hline Day 33 MRD ( $\geq 0.01$ vs. $<0.01 \%$ ) & 1.224 & $0.490-3.060$ & 0.665 & 1.255 & $0.517-3.045$ & 0.615 \\
\hline
\end{tabular}

${ }^{\mathrm{a}} \mathrm{P}<0.001$. ALL, acute lymphoblastic leukemia; RFS, relapse-free survival; HR, hazard ratio; CI, confidence interval; OS, overall survival; TP53, tumor suppressor protein p53; WBC, white blood cell; BM, bone marrow; PB, peripheral blood; CR, complete remission; BCR, breakpoint cluster region; ABL1, ABL proto-oncogene 1, non-receptor tyrosine kinase; MRD, minimal residual disease.
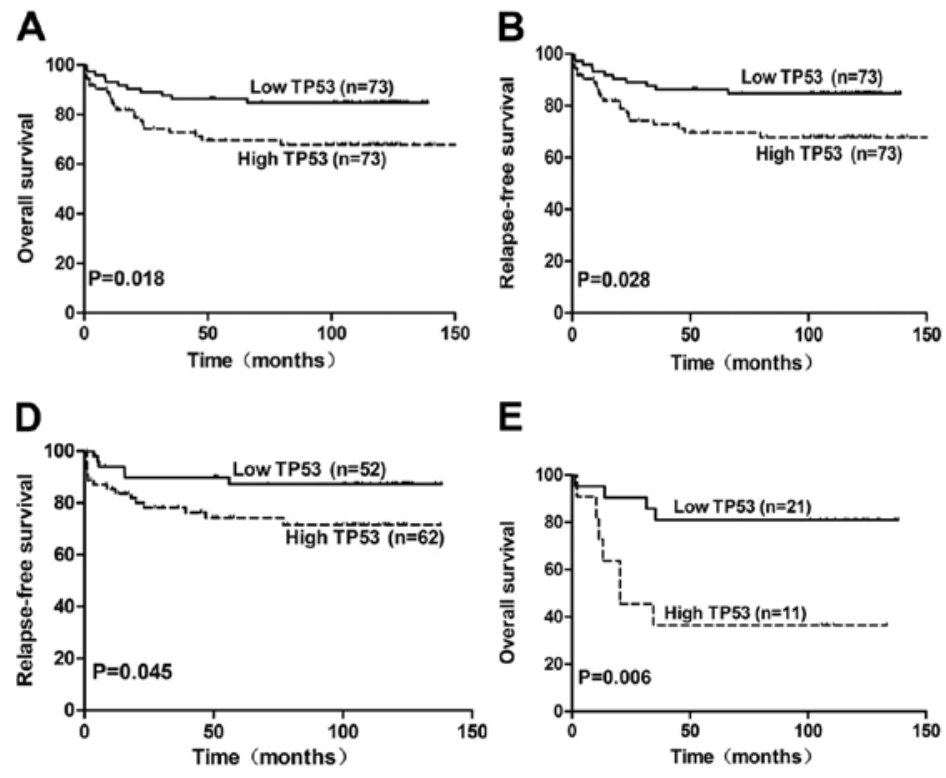

E

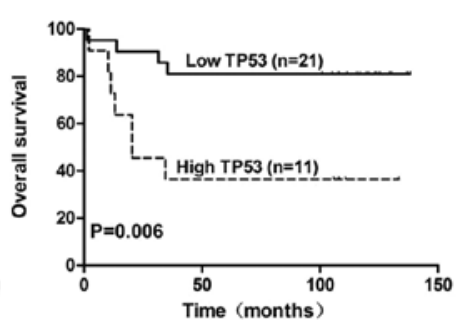

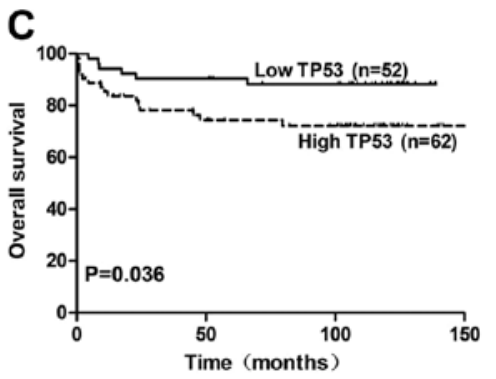

$\mathbf{F}$

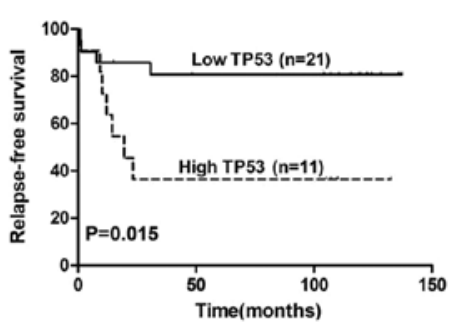

Figure 2. Survival of patients with childhood ALL according to TP53 expression levels. (A) OS in the entire cohort. (B) RFS in the entire cohort. (C) OS in patients with B-ALL. (D) RFS in patients with B-ALL. (E) OS in patients with T-ALL. (F) RFS in patients with T-ALL. Patients who received hematopoietic stem/progenitor cell transplantation were included in the analyses of RFS and OS. ALL, acute lymphoblastic leukemia; TP53, tumor suppressor protein p53; OS, overall survival; RFS, relapse-free survival; B-ALL, B cell ALL; T-ALL, T cell ALL. 
Table IV. TP53 expression in patients with childhood B-ALL.

\begin{tabular}{lccc}
\hline Characteristic & Low TP53 $(\mathrm{n}=52)$ & High TP53 (n=62) & P-value \\
\hline BM blasts, \%, median (range) & $89(72-97)$ & $92(23-98)$ & $0.040^{\mathrm{a}}$ \\
Induction regimen-sensitive, n (\%) & $43(83)$ & $49(79)$ & 0.622 \\
CR, n (\%) & $51(98)$ & $52(84)$ & $0.011^{\mathrm{a}}$ \\
Relapse & $9(18)$ & $12(23)$ & 0.779 \\
5-year RFS, \% (95\% CI) & $87(78-97)$ & $68(59-76)$ & $0.045^{\mathrm{a}}$ \\
5-year OS, \% (95\% CI) & $89(79-98)$ & $75(66-85)$ & $0.036^{\mathrm{a}}$ \\
\hline
\end{tabular}

${ }^{\mathrm{a}} \mathrm{P}<0.05$. B-ALL, B cell acute lymphoblastic leukemia; BM, bone marrow; CI, confidence interval; CR, complete remission; TP53, tumor suppressor protein $\mathrm{p} 53$; RFS, relapse-free survival; OS, overall survival.

Table V. Multivariate analysis of RFS and OS in patients with childhood B-ALL.

\begin{tabular}{|c|c|c|c|c|c|c|}
\hline \multirow[b]{2}{*}{ Factor } & \multicolumn{3}{|c|}{ OS } & \multicolumn{3}{|c|}{ RFS } \\
\hline & HR & $95 \% \mathrm{CI}$ & P-value & HR & $95 \% \mathrm{CI}$ & P-value \\
\hline TP53 expression (high vs. low) & 6.436 & $2.167-19.115$ & $0.001^{\mathrm{a}}$ & 6.026 & $2.050-17.717$ & $0.001^{\mathrm{a}}$ \\
\hline Sex (male vs. female) & 0.973 & $0.392-2.420$ & 0.954 & 0.849 & $0.342-2.109$ & 0.725 \\
\hline Age ( $\geq 10$ vs. $<10$ years $)$ & 2.474 & $0.722-9.626$ & 0.467 & 2.591 & $0.693-9.545$ & 0.374 \\
\hline WBC count $\left(\geq 50 \times 10^{9}\right.$ vs. $<50 \times 10^{9}$ cells $\left./ 1\right)$ & 2.799 & $0.783-10.010$ & 0.113 & 2.115 & $0.640-6.991$ & 0.220 \\
\hline BM blasts ( $\geq$ median vs. $<$ median) & 1.529 & $0.558-4.189$ & 0.409 & 1.464 & $0.541-3.967$ & 0.453 \\
\hline PB blasts ( $\geq$ median vs. $<$ median) & 1.582 & $0.447-5.603$ & 0.477 & 1.977 & $0.610-6.410$ & 0.256 \\
\hline Risk (high vs. low + intermediate) & 2.725 & $0.969-7.663$ & 0.057 & 3.113 & $1.106-8.762$ & $0.032^{\mathrm{a}}$ \\
\hline CR (no vs. yes) & 0.175 & $0.048-0.641$ & $0.008^{\mathrm{a}}$ & 0.257 & $0.073-0.900$ & $0.034^{\mathrm{a}}$ \\
\hline BCR-ABL1 (present vs. absent) & 0.661 & $0.161-2.713$ & 0.565 & 0.609 & $0.148-2.506$ & 0.492 \\
\hline Day 15 MRD ( $\geq 0.01$ vs. $<0.01 \%)$ & 0.726 & $0.276-1.912$ & 0.517 & 0.738 & $0.283-1.924$ & 0.535 \\
\hline Day 33 MRD ( $\geq 0.01$ vs. $<0.01 \%)$ & 1.441 & $0.506-4.105$ & 0.494 & 1.519 & $0.532-4.334$ & 0.435 \\
\hline
\end{tabular}

${ }^{\mathrm{a}} \mathrm{P}<0.05$. B-ALL, B-cell acute lymphoblastic leukemia; RFS, relapse-free survival; HR, hazard ratio; CI, confidence interval; OS, overall survival; WBC, white blood cell; BM, bone marrow; PB, peripheral blood; CR, complete remission; BCR, breakpoint cluster region; ABL1, ABL proto-oncogene 1, non-receptor tyrosine kinase; MRD, minimal residual disease.

control group. When the association between TP53 expression levels and clinicopathological characteristics was analyzed, the results revealed that the high TP53 expression is associated with low percentage of PB blasts and high PLT count. This suggests that high TP53 expression may be a prognostic marker for patients with ALL. Elliott et al (26) have reported that in childhood ALL, circulating peripheral blood blasts rapidly decline in response to the induction of chemotherapy; in addition, prednisone has been identified as an important prognostic factor. Another study demonstrated that the strong association between platelet counts following induction treatment and MRD risk group distribution enabled PLT count to be considered a strong prognostic factor for the improvement of therapeutic risk stratification in trials (27). In addition, from the present study, in patients with childhood B-ALL, high TP53 expression was related to lower BM blasts and poor OS.

The results of the present study have revealed significant associations between the levels of TP53 expression and clinical outcomes; this may help independently predict the prognosis of patients with newly-diagnosed ALL. Patients with low TP53 expression levels were more likely to achieve CR following the induction therapy; the results from the present study revealed a promising 5-year OS of $88 \%$ and 5 -year RFS of $86 \%$. In addition, the results of the present study demonstrated that in 132 patients with B-ALL, BM blasts in the high-TP53 expression group were lower compared with those in the low-TP53 expression group. The high-TP53 expression group also exhibited worse OS and RFS rates compared with the low-TP53 expression group.

In the multivariate analyses, including 11 clinical prognostic factors, high expression of TP53 was an independent predictor for poor OS and RFS in the entire cohort. This indicated that high TP53 expression levels may be considered an adverse prognostic factor for OS and RFS of patients with childhood ALL.

The reasons for increased TP53 expression levels in patients with childhood ALL compared with those in the control group, and for higher TP53 expression in B-ALL compared with that in T-ALL remain uncertain. A feasible explanation would be that TP53 directly activates a core transcriptional program with diverse biological functions, 
which is associated with high-occupancy TP53 enhancers, high levels of paused RNA polymerases and accessible chromatin (28). As TP53 is upregulated in leukemia cells, the likelihood of a gene mutation and loss of antitumor function increases. In addition, high TP53 expression may be an indicator of TP53 loss-of-function due to the impairment of the auto-regulatory feedback loop, which consequently induces TP53-induced protein degradation (29) and directly influences survival in patients with childhood ALL. Additionally, upregulated TP53 expression in B-cell leukemia may be responsible for B cell lineage leukemia activation, and may facilitate TP53 transcription levels to exceed the normal value.

The results of the present study must be interpreted with caution. As this study used a retrospective cohort, a relatively small sample size was used, and all data originated from a single center, which may have biased the analysis. In addition, as all the available samples were transcribed into cDNA in our previous studies, not enough BM tissue was present for immunohistochemical analysis. A multi-center prospective study is needed in the future to verify the results.

In summary, high TP53 expression may be associated with poor prognosis and inferior CR in childhood ALL. TP53 upregulation may be a prognostic and predictive biomarker in patients with childhood ALL.

\section{Acknowledgements}

Not applicable.

\section{Funding}

This study was supported in part by grants from the National Natural Science Foundation of China (grant nos. 81470304 and 81770202) and Key Grants of Zhejiang Provincial Science and Technology Department (grant no. 2019C03032).

\section{Availability of data and materials}

The data that support the findings of this study are available from (Children's Hospital of Zhejiang University School of Medicine, Zhejiang, China) but restrictions apply to the availability of these data, which were used under license for the current study, and so are not publicly available. Data are however available from the authors upon reasonable request and with permission of (Children's Hospital of Zhejiang University School of Medicine).

\section{Authors' contributions}

WW and PZ performed the experiments, data collection and analysis, as well as drafting the manuscript. JR, YZ and DB assisted in completing the statistical analysis. YT designed the study, validated the data and revised the manuscript. All authors read and approved the final manuscript.

\section{Ethics approval and consent to participate}

All treatment protocols were in accordance with the Declaration of Helsinki and approved by the Institutional Review Board of
Ethics of Children's Hospital of Zhejiang University School of Medicine. Written informed consent was obtained from the parents or guardians of all patients.

\section{Patient consent for publication}

Not applicable.

\section{Competing interests}

The authors declare that they have no competing interests.

\section{References}

1. Woo JS, Alberti MO and Tirado CA: Childhood B-acute lymphoblastic leukemia: A genetic update. Exp Hematol Oncol 3: 16, 2014.

2. Tasian SK, Loh ML and Hunger SP: Childhood acute lymphoblastic leukemia: Integrating genomics into therapy. Cancer 121: 3577-3590, 2015

3. Harvey RC, Mullighan CG, Wang X, Dobbin KK, Davidson GS Bedrick EJ, Chen IM, Atlas SR, Kang H, Ar K, et al: Identification of novel cluster groups in pediatric high-risk B-precursor acute lymphoblastic leukemia with gene expression profiling: Correlation with genome-wide DNA copy number alterations, clinical characteristics and outcome. Blood 116: 4874-4884, 2010.

4. Vrooman LM and Silverman LB: Treatment of childhood acute lymphoblastic leukemia: Prognostic factors and clinical advances. Curr Hematol Malig Rep 11: 385-394, 2016.

5. Jaime-Perez JC, Pinzon-Uresti MA, Jimenez-Castillo RA, Colunga-Pedraza JE, Gonzalez-Llano O and Gomez-Almaguer D: Relapse of childhood acute lymphoblastic leukemia and outcomes at a reference center in Latin America: Organomegaly at diagnosis is a significant clinical predictor. Hematology 23: $1-9,2018$.

6. Bhojwani D and Pui CH: Relapsed childhood acute lymphoblastic leukaemia. Lancet Oncol 14: e205-e217, 2013.

7. Bhojwani D, Yang JJ and Pui CH: Biology of childhood acute lymphoblastic leukemia. Pediatr Clin North Am 62: 47-60, 2015.

8. Inaba $\mathrm{H}$, Greaves $\mathrm{M}$ and Mullighan CG: Acute lymphoblastic leukaemia. Lancet 381: 1943-1955, 2013.

9. Bykov VJN, Eriksson SE, Bianchi J and Wiman KG: Targeting mutant p53 for efficient cancer therapy. Nat Rev Cancer 18: 89-102, 2018.

10. Aubrey BJ, Strasser A and Kelly GL: Tumor-suppressor functions of the TP53 pathway. Cold Spring Harb Perspect Med 6: pii: a026062, 2016.

11. Zhukova N, Ramaswamy V, Remke M, Pfaff E, Shih DJ, Martin DC, Castelo-Branco P, Baskin B, Ray PN, Bouffet E, et al: Subgroup-specific prognostic implications of TP53 mutation in medulloblastoma. J Clin Oncol 31: 2927-2935, 2013.

12. Xu P, Liu X, Ouyang J and Chen B: TP53 mutation predicts the poor prognosis of non-Hodgkin lymphomas: Evidence from a meta-analysis. PLoS One 12: e0174809, 2017.

13. Poulain S, Roumier C, Bertrand E, Renneville A, Caillault-Venet A, Doye E, Geffroy S, Sebda S, Nibourel O, Nudel M, et al: TP53 mutation and its prognostic significance in Waldenstrom's Macroglobulinemia. Clin Cancer Res 23: 6325-6335, 2017.

14. Petitjean A, Achatz MI, Borresen-Dale AL, Hainaut P and Olivier M: TP53 mutations in human cancers: Functional selection and impact on cancer prognosis and outcomes. Oncogene 26: 2157-2165, 2007.

15. Zenz T, Eichhorst B, Busch R, Denzel T, Häbe S, Winkler D, Bühler A, Edelmann J, Bergmann M, Hopfinger G, et al: TP53 mutation and survival in chronic lymphocytic leukemia. J Clin Oncol 28: 4473-4479, 2010.

16. ang Y, Xu X, Song H, Yang S, Shi S and Wei J: Long-term outcome of childhood acute lymphoblastic leukemia treated in China. Pediatr Blood Cancer 51: 380-386, 2008.

17. Livak KJ and Schmittgen TD: Analysis of relative gene expression data using real-time quantitative PCR and the 2(-Delta Delta C(T)) method. Methods 25: 402-408, 2001. 
18. Stengel A, Schnittger S, Weissmann S, Kuznia S, Kern W, Kohlmann A, Haferlach T and Haferlach C: TP53 mutations occur in $15.7 \%$ of ALL and are associated with MYC-rearrangement, low hypodiploidy and a poor prognosis. Blood 124: 251-258, 2014.

19. Rabinovich GA, Gabrilovich D and Sotomayor EM: Immunosuppressive strategies that are mediated by tumor cells. Annu Rev Immunol 25: 267-296, 2007.

20. Welch JS, Petti AA, Miller CA, Fronick CC, O'Laughlin M, Fulton RS, Wilson RK, Baty JD, Duncavage EJ, Tandon B, et al: TP53 and Decitabine in acute myeloid leukemia and myelodysplastic syndromes. N Engl J Med 375: 2023-2036, 2016.

21. Stengel A, Kern W, Haferlach T, Meggendorfer M, Fasan A and Haferlach C: The impact of TP53 mutations and TP53 deletions on survival varies between AML, ALL, MDS and CLL: An analysis of 3307 cases. Leukemia 31: 705-711, 2017.

22. Prokocimer M, Molchadsky A and Rotter V: Dysfunctional diversity of p53 proteins in adult acute myeloid leukemia: Projections on diagnostic workup and therapy. Blood 130: 699-712, 2017.

23. Montalban-Bravo G, Takahashi $\mathrm{K}$ and Garcia-Manero $\mathrm{G}$ : Decitabine in TP53-mutated AML. N Engl J Med 376: 796-797, 2017.

24. Bolouri H, Farrar JE, Triche T Jr, Ries RE, Lim EL, Alonzo TA, Ma Y, Moore R, Mungall AJ, Marra MA, et al: The molecular landscape of pediatric acute myeloid leukemia reveals recurrent structural alterations and age-specific mutational interactions. Nat Med 24: 103-112, 2018.
25. Qiu X, You Y, Huang J, Wang X, Zhu H and Wang Z: LAMP3 and TP53 overexpression predicts poor outcome in laryngeal squamous cell carcinoma. Int J Clin Exp Pathol 8: 5519-5527, 2015.

26. Elliott MA, Litzow MR, Letendre LL, Wolf RC, Hanson CA, Tefferi A and Tallman MS: Early peripheral blood blast clearance during induction chemotherapy for acute myeloid leukemia predicts superior relapse-free survival. Blood 110: 4172-4174, 2007.

27. Zeidler L, Zimmermann M, Möricke A, Meissner B, Bartels D, Tschan C, Schrauder A, Cario G, Goudeva L, Jäger S, et al: Low platelet counts after induction therapy for childhood acute lymphoblastic leukemia are strongly associated with poor early response to treatment as measured by minimal residual disease and are prognostic for treatment outcome. Haematologica 97: 402-409, 2012.

28. Andrysik Z, Galbraith MD, Guarnieri AL, Zaccara S, Sullivan KD, Pandey A, MacBeth M, Inga A and Espinosa JM: Identification of a core TP53 transcriptional program with highly distributed tumor suppressive activity. Genome Res 27: 1645-1657, 2017.

29. Muller-Thomas C, Rudelius M, Rondak IC, Haferlach T, Schanz J, Huberle C, Schmidt B, Blaser R, Kremer M, Peschel C, et al: Response to azacitidine is independent of p53 expression in higher-risk myelodysplastic syndromes and secondary acute myeloid leukemia. Haematologica 99: e179-e181, 2014. 